\title{
Evaluation of Sacrum Morphology in Patient with Developmental Dysplasia of the Hip for Iliosacral Screw Fixation
}

Nazım Karahan (D usta_84@hotmail.com )

Corlu State Hospital

Ahmet Oztermeli

Gebze State Hospital

Ahmet Aktan

Gaziosmanpaşa Taksim Eğitim ve Araştırma Hastanesi

\section{Research Article}

Keywords: iliosacral screw, developmental dysplasia of the hip, sacral displasia, cross sectional area, Hartofilakidis

Posted Date: March 4th, 2021

DOI: https://doi.org/10.21203/rs.3.rs-274930/v1

License: (c) (i) This work is licensed under a Creative Commons Attribution 4.0 International License. Read Full License 


\section{Abstract}

Background: The purpose of this study was to evaluate the patients with developmental dysplasia of the hip (DDH) in terms of sacroiliac anatomy to proper placement of iliosacral screws.

Methods: We retrospectively reviewed computed tomography (CT) records of 96 patients who were referred to our clinic. We mainly divided the patients into 2 groups; the iliosacral joint on the same side with DDH evaluated in the DDH group and on the contralateral side with DDH evaluated in the control group. The presence of the five qualitative characteristics of sacral dysplasia evaluated according to Route in both groups. The DDH group divided into three subgroups according to Hartofilakidis and Rout classifications. The cross-sectional area, length of the osseous corridor, coronal and vertical angulation evaluated in both groups.

Results: Sacral dysplasia observed \%87.5 in the DDH group,\%83.3 in the control groups. The DDH group also exhibited a significantly lower S1 cross-sectional area and S1 iliosacral screw length than the control group ( $p: 0.018, p: 0,027$; respectively). No statistically significant difference was observed according to Hartofilakidis $(p>0.05)$. According to Rout, the $S 1$ iliosacral screw length of the normal and transient groups were found to be significantly higher than those of the dysplastic groups ( $p: 0.004, p: 0.0001$; respectively). The transient group also exhibited a significantly lower S1 iliosacral screw length than the normal group (p:0.001). There were no significant differences in S1 and S2 axial and coronal angulation, $S 2$ cross-sectional area, S2 iliosacral screw length in the DDH groups $(p>0.05)$

Conclusion: When iliosacral screw is planned for patients with unilateral DDH, surgeons should consider that there are high rates of dysplastic sacral changes, differences in S1 cross sectional area and iliosacral screw length compared to the opposite side, and asymmetric sacral dysplastic changes in the upper sacrum.

\section{Background}

Percutaneous iliosacral screw fixation is performed in patients with sacroiliac joint dislocations, sacral fractures and some sacroiliac joint fracture dislocations using one or two long screws that pass the midline of the sacrum [1;2]. During percutaneous iliosacral screw fixation, malpositioned implants could damage the neurovascular structures because of interpreting appropriate intraoperative fluoroscopic images, the presence of contrast, intestinal gas, and increased soft tissue density from obesity. Sacroiliac screw fixation even could be contraindicated because of the shape of the sacrum [3]. latrogenic injury occurs frequently in patients with sacral dysplasia $[1 ; 4 ; 5]$.

Developmental dysplasia of the hip is a progressive disease, dysplastic changes of the acetabular fossa and femoral head may be observed in patients with DDH [6;7]. The persistence of hip dysplasia could cause axial skeletal system pathology such as increased lumbar lordosis and scoliosis due to leg length discrepancy and abductor muscle insufficiency [8;9]. Routt et al defined the upper sacral segment morphology that was classified as normal, transitional, and dysplastic, according to the radiological 
characteristics. Routt et al described six qualitative characteristics for the dysmorphic sacrum [10]. Radiological studies have shown that patients with sacral dysplasia have a more narrow and angled osseous corridor in the first sacral segment compared with the normal and transitional groups [11;12]. In the literature, up to $41 \%$ sacral dysplasia has been observed in the normal population but there are variations by ethnicity and gender $[5 ; 12]$.

Imai et al. found that the patients with DDH have different pelvic morphology such as pelvic incidence and anatomical pelvic tilt than the normal population [13]. In patients with preoperative sacral dysmorphism, neurovascular damage occurs at a rate of $0-1 \%$. Patients with sacral dysplasia have small cross-sectional area for safe screws insertion because of angled osseous corridors [14;15]. The relationship between sacral dysplasia and DDH has not been discussed enough in the literature. Defining sacroiliac anatomy is important to proper placement of iliosacral screws in patients with DDH.

The purpose of this study was to evaluate the patients with DDH in terms of sacroiliac anatomy to proper placement of iliosacral screws. The relationship between the severity of dysplasia and the sacral morphology was also evaluated.

\section{Materials And Methods}

We retrospectively evaluated the radiography and CT records of patients who had DDH from January 2011 to September 2020. We found 187 patients with DDH, who had available radiography, and CT records. This retrospective study was approved by the Local Ethics Committee.

\section{Patient selection}

We evaluated the pelvic CT scans of patients aged between 20 and 86 with adequate quality images available on the Picture Archiving Communication system and imaging included the lowest rib-bearing vertebrae and the entire pelvis. We included the patients with unilateral DDH.

The exclusion criteria were : (1) spondylolisthesis; (2) any kyphosis or scoliosis (3) spinal stenosis or sacral agenesis,(4) other reasons of hip dysplasia except for DDH such as cerebral palsy or teratologic hip dysplasia (5) pelvic tumor; (6) skeletal immaturity; (7) general joint laxity ; (8) history of pelvic surgery; (9)lack of available preoperative computer tomography (CT), (10) rheumatological disease which affects spine and pelvis such as ankylosing spondylitis (11) spina bifida,(12) bilateral hip dislocation.

After exclusion criteria were applied 96 patients were selected for the study. We mainly divided the patients into 2 groups; the iliosacral joint on the same side with DDH evaluated in the DDH group and on the contralateral side with DDH evaluated in the control group.

The DDH group divided into three subgroups according to Hartofilakidis Classification. Patients with a femoral head in the acetabulum despite some subluxation with segmental deficiency of the upper wall were named as type A group. Patients in which the femoral head formed a false acetabulum above the 
true acetabulum but the false acetabulum was not completely separated from the true acetabulum was named as type $B$ group. The femoral head was not connected to the true acetabulum was named type $C$ group [16]. The cross-sectional area, length of the osseous corridor, coronal and vertical angulation compared between the groups.

The DDH group and the control group were evaluated according to Rout et al. DDH group also divided into 3 subgroups. According to Rout et al. to compared the cross-sectional area, length of the osseous corridor, coronal and vertical angulation between the groups. The upper sacral segment morphology was evaluated as normal, transitional, and dysplastic as described. Images containing 5 qualitative characters were evaluated as sacral dysplasia which is an upper sacral segment not recessed in the pelvis, the presence of mammillary processes, an acute alar slope, a residual disc between the first and second sacral segments and noncircular upper sacral neural foramina [10]. It was evaluated as normal group without dysplastic characteristics, dysplastic group with all of the dysplastic characteristics, and transient group with less than 5 dysplastic characteristics .

The patient's age, gender, height, weight, diagnosis for which the CT scan had been ordered were recorded (Table 1).

Table 1

The distribution of descriptive characteristics

\begin{tabular}{|ll|}
\hline $\begin{array}{l}\text { Gender } \\
\text { Male }\end{array}$ & $\mathbf{4 0 ( \% 4 1 . 6 )}$ \\
\cline { 2 - 2 } BMI & $\mathbf{5 6}(\% 58.4)$ \\
\hline $\begin{array}{l}\text { DDH Side } \\
\text { Left }\end{array}$ & $24.4 \pm 4.96(18-32)$ \\
Right & $48(\% 50)$ \\
\hline Height(cm) & $48(\% 50)$ \\
\hline $\begin{array}{l}\text { Age(years) } \\
\text { Mean } \pm \text { SD }\end{array}$ & $167 \pm 9.73(151-185)$ \\
\hline DDH: Developmental dysplasia of the hip BMI( body mass index $)$ \\
\hline
\end{tabular}

\section{Data collection}

Demographic data: age, sex, body mass index (BMI), height retrospectively recorded for all study patients. 
To determine the intraobserver reproducibility, intraclass correlation coefficients (ICCs) were calculated by randomly choose 30 patients. These patients were evaluated twice, 10 days apart.

The CTs of all patients were taken in our hospital using high resolution CT with 16 sections (Somatom Emotion; Siemens Healthcare, Germany)For the CT protocol, a 0,625 mm slice intervals while the angle was at $0.1^{\circ}$ with the precision of $0.1 \mathrm{~mm}$ in length was taken. The tomographic images were reconstructed via PACS (picture archiving and communication system) (Infinitt, Korea). For analyzing appropriate the cross-sectional areas and short width of the safe zones, the oblique sagittal images on multiplanar reformation images was used in the same screen that was on contiguous slices perpendicular to the axis of the sacral osseous corridor on axial reformats (1). Coronal angulation was measured, using a line drawn perpendicular to the axis of the osseous corridor and a line connecting the top of the iliac crests. Axial angulation was measured, using a line drawn perpendicular to the axis of the osseous corridor and a line connecting the posterior iliac spines (5)(Fig. 1).

The CT scans were reviewed blindly by a radiologist with at least 5 years experience in musculoskeletal imaging.

\section{Statistical analysis}

Statistical analysis was performed using the SPSS version 25 software (IBM Corporation, Armonk, New York, United States). Data were analyzed using descriptive statistics (mean, standard deviation, median, frequency, percentage, minimum, and maximum). The normal distribution of the data was evaluated using the Shapiro-Wilk test. Variance homogeneity was assessed using the Levene test. The intraobserver reproducibility were determined using intraclass correlation coefficients (ICCs). One-way ANOVA post hoc Tukey test was performed to compare descriptive statistical data (mean, standard deviation, median, frequency, ratio, minimum, and maximum) and quantitative data among the three groups with a normal distribution. The Student's T-test was used for the comparison of the two groups that showed a normal distribution. Pearson correlation coefficients were calculated to analyze the relationship. They were categorized according to Dancey and Reidy grading system as follows: 0 , none; 0.1 to 0.3 , weak; 0.4 to 0.6 , moderate; 0.7 to 0.9 , strong; and 1 , perfect. A p-value $<0.05$ was considered statistically significant.

\section{Results}

No statistically significant difference was observed in S1 and S2 cross-sectional area, S1 and S2 maximum estimated iliosacral screw length, $\mathrm{S} 1$ and $\mathrm{S} 2$ axial and coronal angles assessment by gender, BMI, height, age in both groups $(p>0.05)$.

According to side, The DDH group also exhibited a significantly lower S1 cross-sectional area and S1 iliosacral screw length than the control group ( $p: 0.018, p: 0,027$; respectively). There were no significant differences in S1 and S2 coronal and axial angulation, S2 cross-sectional area and S2 iliosacral screw length between groups (Table 2). 
Table 2

Quantitative measures according to DDH groups and control groups

\begin{tabular}{|llll|}
\hline & *DDH group & Control group & ** \\
\hline $\begin{array}{l}\text { S1 Minimum cross-sectional area } \\
\text { (mm2) }\end{array}$ & $370.03 \pm 84.11$ & $424.7 \pm 80.9$ & 0.027 \\
\hline $\begin{array}{l}\text { S1 Maximum iliosacral screw length } \\
\text { (mm) }\end{array}$ & $\begin{array}{l}82.05 \pm 9.07(67.6- \\
102.4)\end{array}$ & $\begin{array}{l}87.7 \pm 6.69(76.6- \\
104.8)\end{array}$ & 0.018 \\
\hline S1 Axial angulation (deg) & $17.92 \pm 6.95(7.7-31.9)$ & $16.64 \pm 8.34(5.5-30.3)$ & 0.565 \\
\hline S1 Coronal angulation (deg) & $15.7 \pm 6.83(1.8-29.8)$ & $15.14 \pm 5.18(8.2-25)$ & 0.749 \\
\hline $\begin{array}{l}\text { S2 Minimum cross-sectional area } \\
\text { (mm2) }\end{array}$ & $181.3 \pm 54.18$ & $191.7 \pm 56.22$ & 0.538 \\
\hline $\begin{array}{l}\text { S2 Maximum iliosacral screw length } \\
\text { (mm) }\end{array}$ & $54.28 \pm 5.51(43-66.6)$ & $57.3 \pm 8.44(42.20-$ & 0.143 \\
\hline S2 Axial angulation (deg) & $6.97 \pm 4.43(1.8-16)$ & $7.47 \pm 4.57(1.10-20)$ & 0.702 \\
\hline S2 Coronal angulation (deg) & $7.68 \pm 3.35(1.60-15.6)$ & $8.1 \pm 3.8(2.60-15.50)$ & 0.646 \\
\hline *DDH: Developmental dysplasia of the hip & & & \\
\hline *:Student T-test & & & \\
\hline
\end{tabular}

Minimal cross-sectional area, coronal and axial angulation, and maximum estimated iliosacral screw length were significantly greater in the first sacral segment than in the second sacral segment in both groups $(p<0.05)$. In the DDH group, we found no correlation between S1 maximum iliosacral screw length and S2 maximum iliosacral screw length (r:9, p:0.645). A moderate correlation was observed between S1 minimum cross-sectional area and S2 minimum cross-sectional area (r:50, p:0.012). A moderate correlation was observed between S1 axial angulation and S2 axial angulation (r:49, p:0.014).

A moderate correlation was observed between $\mathrm{S} 1$ coronal angulation and $\mathrm{S} 2$ coronal angulation (r:59,p:0.002). In the control groups, we found no correlation between S1 maximum iliosacral screw length and S2 maximum iliosacral screw length, between S1 coronal angulation and S2 coronal angulation, between $\mathrm{S} 1$ axial angulation and S2 axial angulation (p:0.948, p:0.539, p:0.242 ; respectively). A moderate correlation was observed between S1 minimum cross-sectional area and S2 minimum crosssectional area (r:63, p:0.001) (Table 3). 
Table 3

Comparison of quantitative measures with respect to the first sacral and second sacral segment

\begin{tabular}{|lllll|}
\hline First Sacral Second Sacral & \multicolumn{2}{c|}{ Displastic group } & \multicolumn{2}{c|}{ Control group } \\
\cline { 2 - 6 } & $\mathbf{r}$ & $\mathbf{p}$ & $\mathbf{r}$ & $\mathbf{P}$ \\
\hline Minimum cross-sectional area & 50 & 0.012 & 63 & 0.001 \\
\hline Maximum iliosacral screw length & 9 & 0.645 & 2 & 0.948 \\
\hline Coronal angulation & 59 & 0.002 & 13.2 & 0.539 \\
\hline Axial angulation & 49 & 0.014 & 24.8 & 0.242 \\
\hline *Pearson correlation test & & & & \\
\hline
\end{tabular}

According to the Rout classification, $12.5 \%$ were normal, $29.1 \%$ transient, $58.3 \%$ dysplastic on the DDH group. $16.6 \%$ were normal, $41.66 \%$ transient, $41.73 \%$ dysplastic on the control groups. When the DDH group of the patients were divided according to the Rout classification, a statistically significant difference was observed between the $\mathrm{S} 1$ cross-sectional area ( $\mathrm{p}: 0.001)$. According to bilateral comparisons; the $\mathrm{S} 1$ cross-sectional area of the normal and transient groups were found to be significantly higher than those of the dysplastic group ( $p: 0.004, p: 0.0001$; respectively). The transient group also exhibited a significantly lower $\mathrm{S} 1$ cross-sectional area than the normal group (p:0.045). A statistically significant difference was observed in terms of the S1 iliosacral screw length between groups ( $p: 0.001)$. According to bilateral comparisons; the $S 1$ iliosacral screw length of the normal and transient groups were found to be significantly higher than those of the displastic group (p: 0.004, p:0.0001; respectively). The transient group also exhibited a significantly lower S1 iliosacral screw length than the normal group (p:0.001). There was no significant differences in S1 and S2 axial and coronal angulation, S2 cross-sectional area, S2 iliosacral screw length $(p>0.05)$ (Table 4). 
Table 4

Comparison of measurements in the DDH group according to the Rout classification.

\begin{tabular}{|lllll|}
\hline & Normal(N:12) & Transient(N:28) & Displastic(n:56) & $P^{*}$ \\
\hline $\begin{array}{l}\text { S1 Minimum cross-sectional area } \\
\text { (mm2) }\end{array}$ & $523.3 \pm 27.74$ & $393.6 \pm 49.86$ & $325.8 \pm 58.6$ & 0.001 \\
\hline $\begin{array}{l}\text { S1 Maximum iliosacral screw length } \\
(\mathrm{mm})\end{array}$ & $99.26 \pm 2.85$ & $86.01 \pm 4.14$ & $76.37 \pm 5.01$ & 0.001 \\
\hline S1 Axial angulation (deg) & $9.16 \pm 1.3$ & $18.7 \pm 5.73$ & $19.4 \pm 7.05$ & 0.057 \\
\hline S1 Coronal angulation (deg) & $10.86 \pm 2.76$ & $11.3 \pm 6.35$ & $18.94 \pm 6.35$ & 0.016 \\
\hline $\begin{array}{l}\text { S2 Minimum cross-sectional area } \\
\text { (mm2) }\end{array}$ & $266.6 \pm 63.8$ & $197.4 \pm 53.3$ & $155.8 \pm 27.1$ & 0.152 \\
\hline $\begin{array}{l}\text { S2 Maximum iliosacral screw length } \\
\text { (mm) }\end{array}$ & $57.2 \pm 5.88$ & $55.1 \pm 4.32$ & $53.1 \pm 6.03$ & 0.497 \\
\hline S2 Axial angulation (deg) & $3.83 \pm 2.28$ & $7.45 \pm 4.71$ & $7.41 \pm 4.59$ & 0.441 \\
\hline S2 Coronal angulation (deg) & $7.86 \pm 2.95$ & $5.41 \pm 2.52$ & $8.77 \pm 3.40$ & 0.091 \\
\hline *:One Way Anova Tukey test & & & & \\
\hline
\end{tabular}

When DDH group of the patients were divided into groups according to Hartofilakidis, No statistically significant difference was observed in S1 and S2 cross sectional area, S1 and S2 maximum estimated iliosacral screw length, S1 and S2 axial and coronal angles assessment (Table 5).

Table 5

Comparison of measurements in the DDH group according to the Hartofilakidis classification.

\begin{tabular}{|lllll|}
\hline & Type A (n:26) & Type B(n:40) & Type C(n:20) & p* $^{*}$ \\
\hline S1 Minimum cross-sectional area (mm2) & $361.1 \pm 99.6$ & $396.5 \pm 57.3$ & $348.8 \pm 97.4$ & 0.433 \\
\hline S1 Maximum iliosacral screw length (mm) & $81.9 \pm 10.16$ & $83.48 \pm 7.61$ & $80.53 \pm 10.52$ & 0.147 \\
\hline S1 Axial angulation (deg) & $15.21 \pm 5.52$ & $20.65 \pm 7.35$ & $17.2 \pm 7.32$ & 0.057 \\
\hline S1 Coronal angulation (deg) & $14.05 \pm 4.21$ & $15.52 \pm 6.06$ & $17.36 \pm 9.51$ & 0.016 \\
\hline S2 Minimum cross-sectional area (mm2) & $169.18 \pm 39.3$ & $201.7 \pm 41.3$ & $170.5 \pm 74.4$ & 0.152 \\
\hline S2 Maximum iliosacral screw length (mm) & $57.72 \pm 5.84$ & $52.1 \pm 5.1$ & $53.6 \pm 3.43$ & 0.175 \\
\hline S2 Axial angulation (deg) & $5.87 \pm 4.37$ & $8.21 \pm 4.75$ & $6.56 \pm 4.35$ & 0.441 \\
\hline S2 Coronal angulation (deg) & $7.3 \pm 1.54$ & $7.67 \pm 2.13$ & $8.02 \pm 5.42$ & 0.091 \\
\hline *:One Way Anova Tukey test & & & & \\
\hline
\end{tabular}


An ICC value of 0.9 was considered excellent, and values between 0.8 and 0.9 were considered good $[17 ; 18]$. The intraobserver ICCs were 0.82 for the S1 Minimal cross-sectional area, 0.84 for the S1 maximum iliosacral screw length, 0.86 for the $\mathrm{S} 1$ axial angulation, 0.83 for the $\mathrm{S} 1$ coronal angulation, 0.85 for the S2 Minimal cross-sectional area, 0.81 for the S2 maximum iliosacral screw length, 0.80 for the $\mathrm{S} 2$ axial angulation, 0.84 for the $\mathrm{S} 2$ coronal angulation.

\section{Discussion}

The most important finding in our study is that the patients with DDH have upper sacral dysplasia in \%87.5 of the DDH group. S1 cross-sectional area and S1 iliosacral screw length on the DDH groups were significantly lower than the control groups. When patients with developmental hip dysplasia were divided into groups according to the Hartofilakidis classification, no significant difference was observed between the groups in terms of all measurements that were evaluated. There was a moderate correlation between S1 and S2 in terms of cross sectional area, axial angulation and coronal angulation in the DDH group

The upper sacral dysplasia was observed in $12.2-54 \%$ in the population according to literature [10;19]. There is a variation even according to ethnic groups. In the Asian population more sacral dysmorphism was observed than the in western population [1;20]. Mendel et al. showed that S1 cross-sectional area differs according to the side, However, no statistically significant difference was observed [21]. Similarly, other studies showed that the normal population with sacral dysmorphism was symmetric in the radiographs and CT scans [11]. In our study, we observed lower S1 cross-sectional area and iliosacral screw length in the DDH group compared with the control group. According to Rout classification, we observed asymmetrical upper sacral dysmorphism in some patients; sacral dysplasia was observed in $87.5 \%$ ( $29.1 \%$ in the transitional group and $58.3 \%$ in the dysplastic group ) of the DDH group and $83.3 \%$ ( $41.66 \%$ in the transitional group and $41.73 \%$ in the dysplastic group ) of the control group. Especially in cases with asymmetrical dysplastic changes, if it is not planned with proper preoperative preparation, more neurovascular damage may be seen because it could change the intraoperative markers to guide iliosacral screw.

In patients with $\mathrm{DDH}$, the proximal femur has increased anteversion, shortened neck, decreased intramedullary canal size [22], and the acetabulum distorted into an oval shape, and in time, femoral head migrates to the anterosuperior of acetabulum [23]. In cases with dislocated hip, increased lumbar Iordosis, scoliosis and valgus deformity of the knee joint may be observed clinically [8;24]. That causes changes in the coronal alignment of the hip and knee joints in patients with DDH [25]. The pelvic incidence and anatomical sacral slope changes were observed in patients with DDH [13]. Malalignment of the lower extremity may result from soft tissue or structural bone problems. On the other hand, since the grade of hip dislocation is proportional to the lower extremity malalignment [26]. We expected more dysplastic changes at higher grades of dislocations. In our study, no relation was found between grades and dysplastic changes. On the other hand, the higher rate of sacrum dysplasia in the normal side 
suggests that the DDH process creates changes on the opposite side even in unilateral DDH cases. This suggests that more detailed studies should be conducted to reveal the etiology of sacral dysplasia in patients with DDH.

In the literature, a connection was observed between sacral dysmorphic changes in $\mathrm{S} 1$ cross sectional area and S1 iliosacral screw length in the normal population. In the study by Kım et al., It was observed that the S1 cross-sectional area was higher in the normal group compared to the transient and dysplastic group according to the rout classification [1]. In Kaiser et al. study less cross-sectional area and iliosacral screw length were observed in people with dysplastic changes [5]. Similarly, in our study, less S1 crosssectional area and iliosacral screw length were observed in the dysplastic group compared to the transient and normal groups. However, no change was observed in S2 cross-sectional area and S2 iliosacral screw length according to the groups.

In the literature, iliosacral screw length, cross-sectional area, and axial and coronal angulations are controversial in terms of gender in the normal population. There are studies showing that women have less cross-sectional area, iliosacral screw length and less coronal and axial angulation than men [19;21]. On the other hand, there are studies showing that there is no relation with gender [21;27]. In our study, There was no relation between gender and all these measurements between the groups. In Balling et al.' study, it was observed that there were no gender-related changes in hips with upper sacral dysmorphism [27]. Since most of the patients in our study were upper sacral dysmorphism, it may be the reason why there were no gender-related changes.

Coronal and axial angulations were higher in the sacrums with dysplastic changes. In the dysmorphic sacrum, the upper sacral screw iliac cortical starting point is posterior and caudally located.

Hasenboehler et al. previously reported the mean axial angulations was $19.27^{\circ}$ for $\mathrm{S} 1$ [19]. Kaiser et al's study the mean axial angulations was $11 \pm 10.5$, the mean coronal angulation was $22.6 \pm 11.1$ for $\mathrm{S} 1$ [5]. Gardner et al's study the normal sacrum's axial angulation was $4.2 \pm 3.60$ and the dysplastic sacrum was $14.9 \pm, 9.0$, the normal sacrum's coronal angulation was $20.5 \pm 6.3$ and the dysplastic sacrum was $30.3 \pm$ 4.6 [12]. In our study, the mean axial angulations was $17.92 \pm 6.95$ the normal $\mathrm{S} 1$ axial angulations was $9.16 \pm 1.3$ and dysplastic sacrum's axial angulation was $19.4 \pm 7.05$, the mean coronal angulation was $15.7 \pm 6.83$ the normal sacrum's coronal angulation was $10.86 \pm 2.76$ and the dysplastic sacrum was $18.94 \pm 6.35$. These results are similar to literature.

In the study of Kaiser et al., It has been shown that the S1 cross sectional area, iliosacral screw length, and axial and coronal angles are greater than the S2 measurements [5]. On the other hand, Garden et al. showed that in dysplastic sacrums, cross-sectional area, iliosacral screw length and axial and coronal angles are the same in the S1 and S2 [12]. In our study, although $87.5 \%$ of the patients had dysplastic changes, we found significantly higher results in all measurements between S1 and S2. This difference suggests that the dysplastic changes caused by DDH are different from normal populations but further studies are needed to determine this suggestion. In addition, it was observed that a positive correlation was found with the cross-sectional area, axial and coronal angulation between S1 and S2 in DDH group. 
This suggests that in patients with DDH, changes due to DDH occur not only in the first sacrum but also in the second sacrum at a similar rate.

The number of screws and screw diameter affect the iliosacral screw length. Long screws can be placed from the posterolateral to the anteromedial direction [20;28]. The screw diameters used in daily practice are $6.3,7$ and $8 \mathrm{~mm}$, the screw diameters should be selected to leave a safe osseous distance around the screw. There are lots of studies investigating the measurements by different screw numbers and screw diameters [12;29;30]. In our study, we measured vertical and posterior locations which are available for 8 $\mathrm{mm}$ diameter iliosacral screws. The majority of patients in our study were dysplastic and had less crosssectional area, suggesting that multiple screws are less likely. We chose $2 \mathrm{~mm}$ higher diameter to have sufficient bone stock. Therefore, a thickness of $10 \mathrm{~mm}$ area has been preferred to suit the single $8 \mathrm{~mm}$ screw.

In the Rout et al cadaver study, those whose hips did not show dysplastic changes were normal, those who showed all dysplastic changes were dysplastic, and those who did not show all dysplastic changes were included as transient. Six qualitative characteristics were associated with the dysmorphic sacrum [10]. On the other hand, in a study showed that the tongue-in-groove was a less reliable marker for dysmorphism [5] so in our study, when evaluating sacrum dysplasia, the tongue-ingroove was not accepted as one of the characteristics. Routt et al used the radiographic outlet images to define sacral dysmorphism [10]. In our study, computer tomography was chosen over conventional radiography because sacral dysmorphism could also result from differences in radiographic image used for evaluation of sacral dysplasia [5].

The most important limitation in our study was we included only patients with unilateral DDH because we could not find enough patients with bilateral DDH. Second, all the patients were of Caucasian descent. It has been shown in the literature that ethnic differences have an impact on sacrum morphology. Further studies are needed for different ethnic groups. Another limitation is that it has been observed that 6 characteristic dysplastic characteristics have moderate interobserver reliability in order to classify according to rout classification [5]. In our study, although strong intraobserver reliability was observed in the evaluation made with a single observer, it is thought that the evaluations made with different observers may affect the results.

\section{Conclusion}

When iliosacral screw is planned for patients with unilateral DDH, surgeons should consider that there are high rates of dysplastic sacral changes, differences in S1 cross-sectional area and iliosacral screw length compared to the opposite side, and asymmetric sacral dysplastic changes in the upper sacrum.

\section{Declarations}

\section{Ethics approval and consent to participate}


The study has been performed in accordance with the Declaration of Helsinki and ethical approval was obtained from the local ethics committee (Taksim Gaziosmanpasa Education Research Hospital Ethics Committee Decision no: 2020-153). Written informed consent was obtained from all participants.

\section{Consent for publication}

The authors have received written consent from participants to publish individual data.

\section{Availability of data and materials}

The datasets used and/or analyzed during the current study are available from the corresponding author on reasonable request.

\section{Competing interests}

The authors declare that they have no conflict of interest.

\section{Funding}

No financial funding sources were acquired for this study.

\section{Authors' contributions}

N.K. and A.O. conceived of the presented idea. N.K. developed the theory and performed the computations. A.A evaluated the CT. N.K and A.A. verified the analytical methods. N.K. and A.O. wrote the manuscript with input from all authors. All authors discussed the results and contributed to the final manuscript

\section{Acknowledgements}

Not applicable.

\section{References}

1. Kim J-J, Jung C-Y, Eastman J, Oh H-K. Measurement of optimal insertion angle for lliosacral screw fixation using three-dimensional computed tomography scans. Clin Orthop Surg. 2016;8(2):133-9.

2. Nork SE, Jones CB, Harding SP, Mirza SK, Routt MLC. Percutaneous stabilization of U-shaped sacral fractures using iliosacral screws: technique and early results. J Orthop Trauma. 2001;15(4):238-46.

3. Ilharreborde B, Breitel D, Lenoir T, Mosnier T, Skalli W, Guigui P, et al. Pelvic ring fractures internal $\mathrm{fi}$ xation: Iliosacral screws versus sacroiliac hinge fi xation. Orthop Traumatol Surg Res 2009;95:563-7.

4. Miller AN, Routt ML Jr. Variations in sacral morphology and implications for iliosacral screw fixation. J Am Acad Orthop Surg. 2012;20(1):8-16. 
5. Kaiser SP, Gardner MJ, Liu J, Routt ML Jr, Morshed S. Anatomic determinants of sacral Dysmorphism and implications for safe Iliosacral screw placement.J Bone Joint Surg Am. 2014;96(14):e120.

6. Clohisy JC, Dobson MA, Robison JF, Warth LC, Zheng J, Liu SS, et al. Radiographic structural abnormalities associated with premature, natural hip-joint failure. J. Bone Joint Surg Am. 2011;93(Suppl 2):3-9.

7. van Bosse H, Wedge JH, Babyn P. How are dysplastic hips different? A three-dimensional CT study. Clin Orthop Relat Res. 2015;473:1712-23.

8. Crowe JF, Mani VJ, Ranawat CS. Total hip replacement in congenital dislocation and dysplasia of the hip. J Bone Joint Surg Am 1979;61:15-23. .

9. Weinstein SL. Natural history of congenital hip dislocation (CDH) and hip dysplasia. Clin Orthop. Relat Res 1987;225:62-76. .

10. Routt ML Jr, Simonian PT, Agnew SG, Mann FA.Radiographic recognition of the sacral alar slope for optimal placement of iliosacral screws: a cadaveric and clinical study. J Orthop Trauma. $1996 ; 10(3): 171-7$.

11. Conflitti JM, Graves ML, Chip Routt ML Jr. Radiographic quantification and analysis of dysmorphic upper sacral osseous anatomy and associated iliosacral screw insertions. J Orthop Trauma. 2010 Oct;24(10):630-6.

12. Gardner MJ, Morshed S, Nork SE, Ricci WM, Chip Routt ML Jr. Quantification of the upper and second sacral segment safe zones in normal and dysmorphic sacra J Orthop Trauma. 2010 Oct;24(10):6229.

13. Imai N, Miyasaka D, Tsuchiya K, Suzuki H, Ito T, Minato I, et al. Evaluation of pelvic morphology in female patients with developmental dysplasia of the hip using three-dimensional computed tomography: A cross-sectional study. J Orthop Sci. 2018 Sep;23(5. ):788-92.

14. Schweitzer D, Zylberberg A, C'ordova M, Gonzalez J. Closed reduction and iliosacral percutaneous fixation of unstable pelvic ring fractures. Injury. 2008Aug;39(8):869-74.

15. Gardner MJ, Farrell ED, Nork SE, Segina DN, Routt ML Jr. Percutaneous placement of iliosacral screws without electrodiagnostic monitoring. J Trauma. 2009 May;66(5):1411-5.

16. Hartofilakidis G, Lampropoulou-Adamidou K. Lessons learned from study of congenital hip disease in adults. World J Orthop. 2016 Dec 18;7(12):785-92.

17. Altman DG. Practical statistics for medical research,1 st edn.Chapman and Hall,London;Newyork. 1991 p xii 611 p. p.

18. Cicchetti DV. Guidelines, criteria, and rules of thumb for evaluating normed and standardized assessment instruments in psychology. Psychol Assess. 1994;6:284-90.

19. Hasenboehler EA, Stahel PF, Williams A, Smith WR, Newman JT, Symonds DL, et al. Prevalence of sacral dysmorphia in a prospective trauma population: Implications for a "safe" surgical corridor for sacro-iliac screw placement. Patient Saf Surg. 2011 May. 10;5(1):8. 
20. Wu LP, Li YK, Li YM, Zhang YQ, Zhong SZ. Variable morphology of the sacrum in a Chinese population. Clin Anat.2009;22(5):619-26.

21. Mendel T, Noser H, Kuervers J, Goehre F, Hofmann GO, Radetzki F. The influence of sacral morphology on the existence of secure S1 and S2 transverse bone corridors for iliosacroiliac screw fixation. Injury. 2013 Dec;44(12):1773-9.

22. Wells J, Nepple JJ, Crook K, Ross JR, Bedi A, Schoenecker P, et al.Femoral Morphology in the Dysplastic Hip: Three-dimensional Characterizations With CT. Clin Orthop Relat Res. 2017 Apr;475(4):1045-54.

23. Nepple JJ, Wells J, Ross JR, Bedi A, Schoenecker PL, Clohisy JC.Three Patterns of Acetabular Deficiency Are Common in Young Adult Patients With Acetabular Dysplasia. Clin Orthop Relat Res. 2017 Apr;475(4):1037-44.

24. Li Q, Kadhim M, Zhang L, Cheng X, Zhao Q, Li L. Knee joint changes in patients with neglected developmental hip dysplasia: a prospective case-control study. Knee 2014;21(6):1072-6.

25. Kilicarslan K, Yalcin N, Cicek H, Cila E, Yildirim H. What happens at the adjacent knee joint after total hip arthroplasty of Crowe type III and IV dysplastic hips? J Arthroplasty. 2012;27(2):266-70.

26. Kocabiyik A, Misir A, Kizkapan TB, Yildiz KI, Kaygusuz MA, Alpay Y,et al. Changes in Hip, Knee, and Ankle Coronal Alignments After Total Hip Arthroplasty With Transverse Femoral Shortening Osteotomy for Unilateral Crowe Type IV Developmental Dysplasia. of the Hip. J Arthroplasty. 2017 Nov;32(11):3449-56.

27. Balling H. Gender-Associated Differences in Sacral Morphology Do Not Affect Feasibility Rates of Transsacral Screw Insertion. Radioanatomic Investigation Based on Pelvic Cross-sectional Imaging of 200 Individuals. Spine (Phila Pa 1976). 2020 Apr 1;45(7):. 421-30.

28. Day CS, Prayson MJ, Shuler TE, Towers J, Gruen GS. Transsacral versus modified pelvic landmarks for percutaneous iliosacral screw placement: a computed tomographic analysis and cadaveric study. Am J Orthop (Belle Mead NJ). 2000;29(9 Suppl):16-21.

29. Ziran $B H$, Wasan AD,Marks DM, Olson SA, Chapman MW. Fluoroscopic imaging guides of the posterior pelvis pertaining to iliosacral screw placement. J Trauma. 2007 Feb;62(2):347-56; discussion 356.

30. Moed BR, Geer BL. S2 iliosacral screw fixation for disruptions of the posterior pelvic ring: a report of 49 cases. J Orthop Trauma. 2006 Jul;20(6):378-83.

\section{Figures}



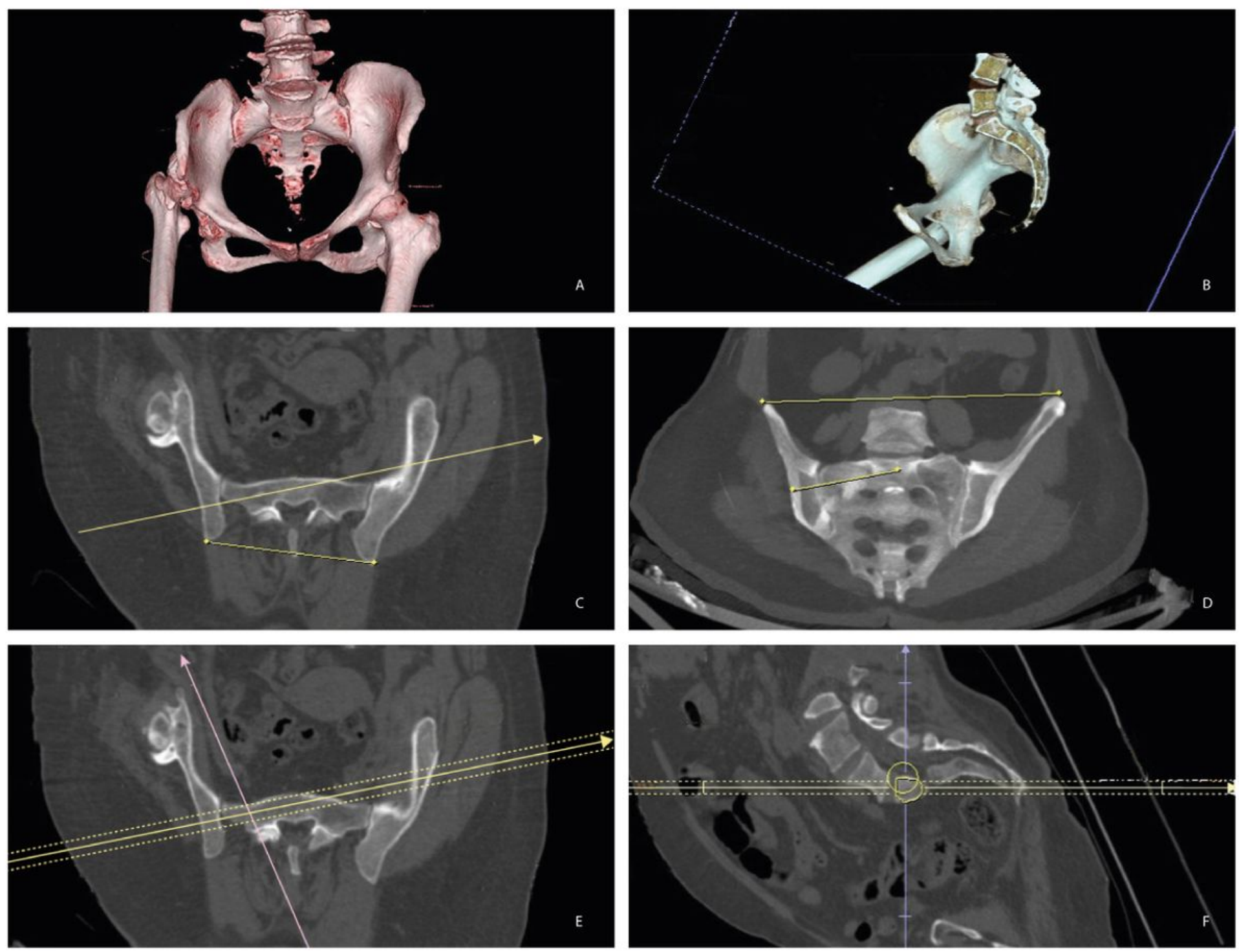

\section{Figure 1}

$3 \mathrm{D}$ pelvic $\mathrm{CT}$ reconstruction images were analyzed in a 55-year-old patient with right unilateral $\mathrm{DDH}$. A-)Bilateral sacral dysmorphism, DDH on the right side are seen B. More than half of the S1 body located above the iliac cortical density on the right. $\mathrm{C}$ ve $\mathrm{D}$ axial and coronal reformats made perpendicular to the S1 and S2 sacral osseous corridors. Axial and coronal angulations of the first and second sacral segments were measured. E. The maximum length of a $10 \mathrm{~mm}$ diameter osseous corridor measured. $\mathrm{F}$. Sagittal computed tomography image showing the cross-sectional area of the safe zone. 